\title{
Lyophilisates for drug delivery in ophthalmology: pharmacokinetics of fluorescein in the human anterior segment
}

\author{
S Dinslage, M Diestelhorst, A Weichselbaum, R Süverkrüp
}

Br J Ophthalmol 2002;86:1 114-1117

\begin{abstract}
Aims: To assess the ocular bioavailability of fluorescein from a novel water free, freeze dried ophthalmic drug delivery system compared to conventional preservativefree fluorescein eye drops.

Methods: Sodium fluorescein $0.17 \%$ was dissolved in an aqueous solution of hydroxypropylmethyl cellulose 1.0\% (HPMC), deposited on sterilised flexible hydrophobic poly(tetrafluoroethylene) (PTFE) carrier strips and freeze dried under aseptic conditions. The fluorescein dose of the lyophilisate was $68 \mu \mathrm{g}$, corresponding to a single conventional drop of $40 \mu$ f fluorescein $0.17 \%$ solution. In a randomised, open label study 12 healthy volunteers applied the lyophilised fluorescein to one eye and one drop of conventional fluorescein ophthalmic solution to the fellow eye. Fluorophotometry measurements of fluorescein concentrations in the anterior segment were performed with the Fluorotron Master II (Ocumetrics, USA) before and $+15,30,45,60,120$, and 180 minutes after application. Results: At all times anterior chamber fluorescein concentration was greater in the lyophysilate treated eye than the solution treated eye. The magnitude of this difference ranged from 2-5.3 times and was statistically significant. Conclusion: The greater intraocular bioavailability of fluorescein from the lyophilisate relative to the solution suggests that it may be a useful method for delivering substances to the eye.
\end{abstract}

\footnotetext{
C
} onventional eye drops, used in most medications for ocular treatment, have several disadvantages. Even for experienced users it is difficult to administer a single drop to the right place. Elderly patients or children even without impaired manual skills even injure their eyes and cause bacterial contamination upon contact with the bottle tip. Preservatives are known to cause morphological changes of the cornea, conjunctiva, and Tenon leading to changing in scarring behaviour after glaucoma surgery. ${ }^{1-3}$ Preservatives cause irritation such as burning, stinging, tearing, hyperaemia, and punctate keratitis and allergies, a common ocular side effect of conventional eye drops. Preservatives and $\mathrm{pH}$ adjustments are required to dissolve the drugs (for example, homatropine, pilocarpine, etc) and to maintain their chemical stability. Both are responsible for increased tear flow, thus diluting the applied medication which results in poor pharmacokinetics of conventional eye drops. ${ }^{4}$

In the recent past drug delivery devices like the Ocusert and NODS (new ophthalmic drug delivery system) have been demonstrated to be safe and tolerated in the human eye, as well as being efficient delivery systems. ${ }^{5-8}$ However, none of them has been used therapeutically on a broad scale. Thus, we continue to search for the ideal delivery system which should be constant in its dose delivery, easy to handle, of minimal
Figure 1 Application of a fluorescein lyophilisate. The fluorescein is deposited on the lower cul de sac by stripping the lyophilisate off over the rim of the lower lid in a wiping motion. The head is not reclined. The wiping motion is known to everybody.

discomfort and effect on precorneal clarity, pH neutral, sterile, and preservative free.

A new ophthalmic drug delivery device (lyophilisate) was developed. The medication is dissolved with a hydrophilic polymer and freeze dried at the tip of a soft hydrophobic carrier strip. The drug is deposited at the conjunctiva by stripping the lyophilisate off the carrier in a wiping motion over the rim of the lower eyelid (Fig 1). In the present study we used sodium fluorescein to compare the pharmacokinetics of conventional preservative-free eye drops and lyophilisate measured by fluorophotometry. The distribution of sodium fluorescein from the tear film to the cornea and aqueous humour was measured to assess the pharmacokinetics of the new application form.

\section{METHODS}

Fluorescein was dissolved in an aqueous solution of hydroxypropylmethyl cellulose $1.0 \%$ (HPMC, Methocel E50) filtered through a $0.22 \mu \mathrm{m}$ mixed cellulose ester filter and deposited onto a steam sterilised flexible hydrophobic poly(tetrafluoroethylene) (PTFE) carrier strip at a laminar flow workbench. The strips were deep frozen at $-30^{\circ} \mathrm{C}$ for 45 minutes and freeze dried (Christ alpha 2-4, Osterode, Germany) for 2 hours at 1.2 mbar under aseptic conditions and packed aseptically in presterilised test tubes.

We applied the fluorescein lyophilisate at a dose of $68 \mu \mathrm{g}$ and used a single conventional fluorescein solution of $40 \mu \mathrm{l}$ (Fluoreszein $0.17 \%$ SE Thilo) as a control agent. Twelve bilateral, healthy volunteers were enrolled. None of the volunteers had a previous history of eye disease, local or systemic medication, contact lens wear, and myopia or hyperopia of $>6$ dioptres. None of the volunteers had applied the new drug device before. After written informed consent each subject applied a single drop $(40 \mu \mathrm{l})$ to one eye and the lyophilisate to 


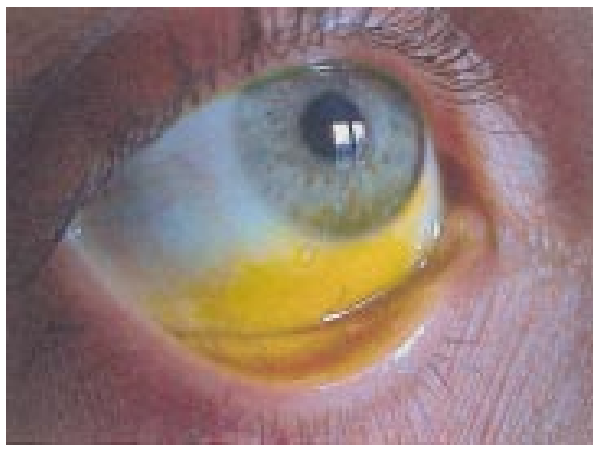

Figure 2 Fluorescein lyophilisate at the conjunctival fornix after application. The picture shows fluorescein uptake of the cornea and conjunctiva after 5 minutes.

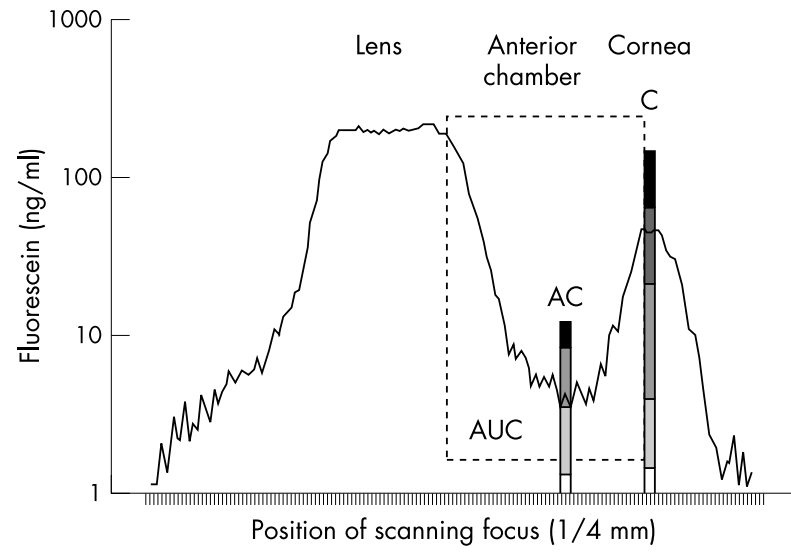

Figure 3 Fluorophotometry measurement with fluorescein analysis area of precorneal tear film (C), anterior chamber (AC), and space from corneal endothelium to anterior lens surface (AUC).

the contralateral eye in a randomised manner. The fluorescein was deposited at the cul de sac by stripping the lyophilisate off the carrier in a wiping motion (Fig 1). Upon contact with the conjunctiva the lyophilisate rehydrates rapidly in the tear film (Fig 2).

Fluorophotometry of the anterior segment was performed with the Fluorotron Master II (Ocumetrics, USA). Measurements were taken before and $+15,30,45,60,120$, and 180 minutes after administration. Fluorescein concentrations of the precorneal tear film (C), mid anterior chamber (AC), and area under the curve from cornea peak to the anterior lens surface (AUC) were evaluated (Fig 3). The statistical differences of the fluorescein concentrations of $\mathrm{C}, \mathrm{AC}$, and AUC were compared by one way ANOVA $(p \leqslant 0.05)$.

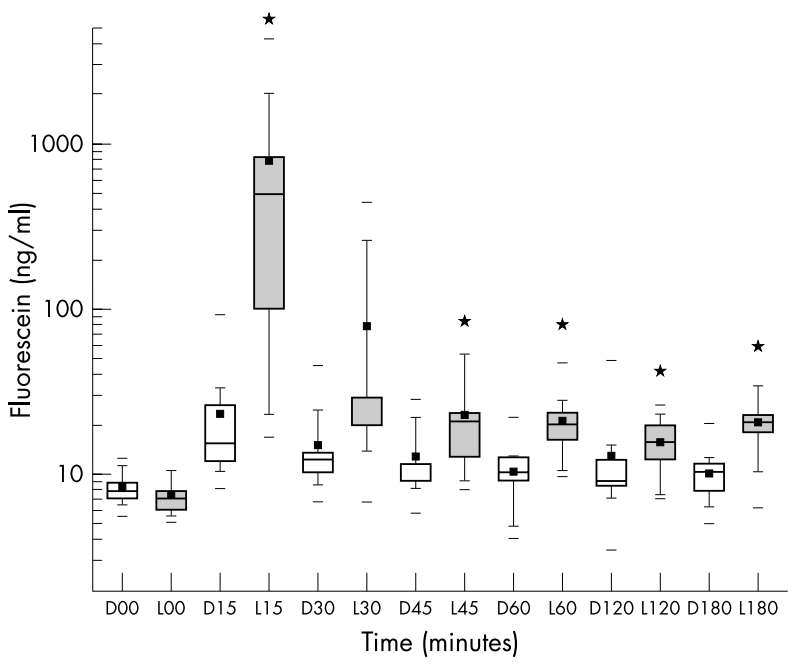

Figure 4 Box plot diagram of precorneal fluorescein concentrations (C) in $\mathrm{ng} / \mathrm{ml}$ over time after drop (D) application (open boxes) and lyophilisate (L) application (grey boxes) $(n=12)$. ${ }^{*}$ Marks a statistical difference $(p \leqslant 0.05)$.

\section{RESULTS}

Twelve healthy volunteers (seven men, five women; aged 23-33 years) successfully completed the protocol. The autofluorescence of all eye-fluorescein profiles before application showed no statistical differences (fluorescein precorneal: $8.25 \mathrm{ng} / \mathrm{ml}$ (drop); $7.45 \mathrm{ng} / \mathrm{ml}$ (lyophilisate); fluorescein anterior chamber: $3.58 \mathrm{ng} / \mathrm{ml}$ (drop); $2.60 \mathrm{ng} / \mathrm{ml}$ (lyophilisate)). All volunteers were able to readily deposit the lyophilisate to the lower cul de sac without signs or symptoms of irritation.

\section{Precorneal tear film concentration (C)}

All mean fluorescein concentrations of the precorneal tear film were higher in the lyophilisate group compared to the precorneal tear film after eye drop application (Fig 4). Concentration differences were statistically significant at +15 , 45, 60, and 180 minutes after administration $(p \leqslant 0.05$, Table $1)$. The higher concentration factor post-lyophilisate application ranged from $33.7 \times(15$ minutes $)$ to $1.3 \times$ ( 120 minutes $)$.

\section{Anterior chamber concentration (AC)}

The mid-anterior chamber mean fluorescein concentrations were higher in the lyophilisate group (Fig 5). Values at +15 , $30,45,60,120,180$ minutes after administration were statistically significant $(\mathrm{p}<0.05)$. The higher concentration factor post-lyophilisate application ranged from $5.3 \times$ ( 15 minutes) to $2.0 \times(60$ minutes). In the lyophilisate group the mean fluorescein concentration increased up to 3 hours after administration (Table 1).

Table 1 Mean fluorescein concentrations $(\mathrm{ng} / \mathrm{ml}$ ) of cornea (C), anterior chamber (AC), and integral from corneal endothelium to anterior lens surface (AUC) over time after drop and lyophilisate application $(n=12)$

\begin{tabular}{|c|c|c|c|c|c|c|}
\hline \multirow[b]{2}{*}{ Time (minutes) } & \multicolumn{2}{|c|}{ Cornea (C) } & \multicolumn{2}{|c|}{ Anterior chamber (AC) } & \multicolumn{2}{|c|}{ Area cornea-lens (AUC) } \\
\hline & Drop & Lyophilisate & Drop & Lyophilisate & Drop & Lyophilisate \\
\hline 0 & 8.25 & 7.45 & 3.58 & 2.60 & 1223.76 & 1168.97 \\
\hline 15 & 23,23 & $772.88 *$ & 7.65 & $26.27 *$ & 1405.93 & $7161.68 *$ \\
\hline 30 & 14.89 & 78.80 & 4.40 & $6.11^{*}$ & 1310.47 & 1749.74 \\
\hline 45 & 12.50 & 23.22 * & 4.40 & $6.64^{*}$ & 1338.95 & 1469.35 \\
\hline 60 & 10.41 & $20.88^{*}$ & 5.18 & $7.98^{*}$ & 1285.89 & 1426.35 \\
\hline 120 & 12.94 & 15.81 * & 5.53 & $11.52 *$ & 1394.21 & 1537.00 \\
\hline 180 & 10.23 & 20.91 * & 5.24 & $13.12^{*}$ & 1340.62 & $1686.18^{*}$ \\
\hline
\end{tabular}




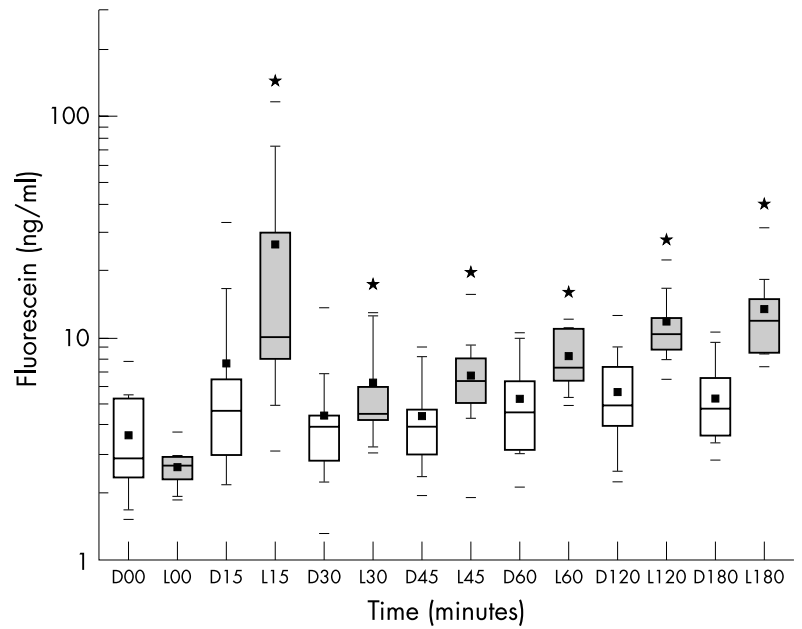

Figure 5 Box plot diagram of anterior chamber fluorescein concentrations ( $A C$ ) in $\mathrm{ng} / \mathrm{ml}$ over time after drop (D) application (open boxes) and lyophilisate (L) application (grey boxes) $(n=12)$. ${ }^{*}$ Marks a statistical difference $(p \leqslant 0.05)$.

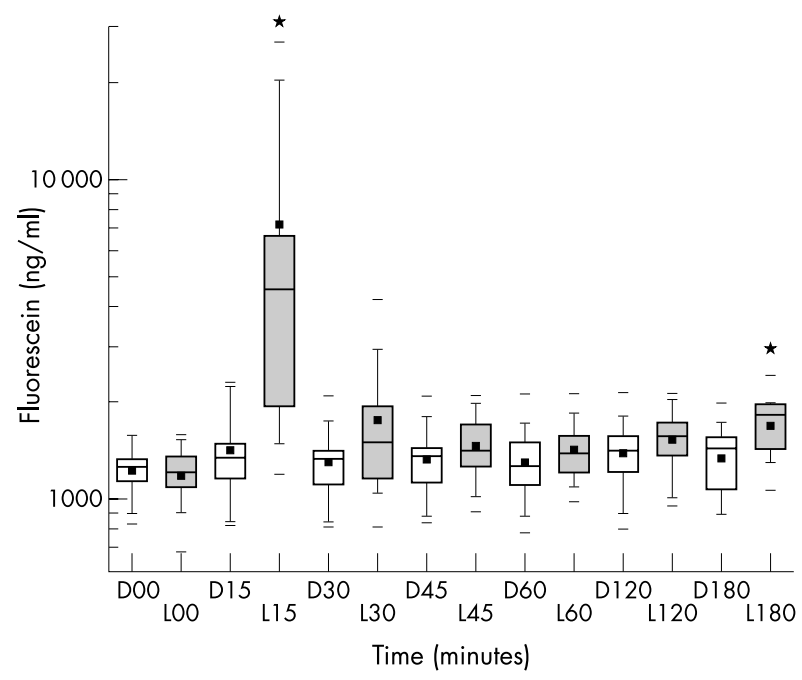

Figure 6 Box plot diagram of fluorescein concentrations from cornea to lens (area under the curve $=A U C$ ) in $\mathrm{ng} / \mathrm{ml}$ over time after drop (D) application (open boxes) and lyophilisate (L) application (grey boxes) $(n=12)$. *Marks a statistical difference $(p \leqslant 0.05)$.

\section{Area under the curve, cornea-anterior lens surface (AUC)}

All mean fluorescein concentrations from corneal endothelium to anterior lens surface were higher in the lyophilisate group (Fig 6). Values at +15 and 180 minutes after administration were statistically significant $(\mathrm{p}<0.05)$. The higher concentration factor post-lyophilisate application ranged from $5.2 \times(15$ minutes $)$ to $2.3 \times$ ( 180 minutes $)$.

\section{DISCUSSION}

Our objective was to compare the pharmacokinetics of equivalent fluorescein doses from lyophysilate and conventional solution.

The efficiency of drug absorption depends on the adequate mixing of drug with the precorneal tear film and the residence time of the drug in the precorneal area..$^{9-11}$ The rate of drug concentration decline in the tears is proportional to the amount of drug remaining in the tears over time; thus, it approximates first order kinetics. Most eye drops exhibit similar apparent times to peak concentration in aqueous humour as the material drains out of the cul de sac within the first 5 minutes. Therefore, the time frame for most drugs to reach their peak concentration in the aqueous humour falls within a rather narrow range of 20-60 minutes. ${ }^{12}{ }^{13}$

The eye drop volume delivered from commercial product containers varies from $25-50 \mu \mathrm{l}$, but can be as high as $75 \mu \mathrm{l}$ depending on the size of the bottle's tip, temperature, elasticity of the container, and force of the patient. ${ }^{14-16}$ During instillation $25-50 \mu \mathrm{l}$ are added to the precorneal tear film, the greater part rapidly drains via the nasolacrimal duct to the nasal mucosa causing systemic side effects. The solution returns to the normal resident tear volume of approximately $7-9 \mu \mathrm{l} .{ }^{17}$ At least $80 \%$ of the applied medication leaves via lacrimal drainage and does not reach the inner eye. ${ }^{18} 19$ Instillation of eye drops stimulates lacrimation and increases the turnover rate up to $30 \%$ per minute. Stinging and foreign body sensation of preserved drugs upon instillation produces a higher rate of loss because of reflex tearing. ${ }^{20}$ About $90 \%$ of eye medications prescribed today contain preservatives which are cytotoxic to the ocular surface to different degrees..$^{21} 22$ Their cytotoxicity leads to epithelial desquamation and increased permeability. In cell cultures preservatives induce apoptosis at low concentrations and necrosis at high concentrations. ${ }^{23}{ }^{24}$ In animals, chronic instillation of preservatives leads to the onset of inflammatory conjunctival infiltrates and damage to many mucous cells. ${ }^{25}{ }^{26}$ These results are similar to those observed in humans after chronic use of antiglaucoma eye drops. It was found that long term use of antiglaucoma medication induces changes in tear film and conjunctival surface which leads to a significant degree of subclinical inflammation. ${ }^{27} 28$

Since we used fluorescein, we could study non-invasively both the precorneal (extraocular) and the anterior chamber (intraocular) concentration of the dye over time. By means of lyophilisate application higher values of fluorescein were found in the precorneal tear film and in the anterior chamber over 3 hours in human eyes. We were able to measure fluorescein concentrations from lyophilisate at least twice as high as in eyes after eye drop administration. Concentrations in the anterior chamber were up to 5.3 times higher after 15 minutes in the lyophilisate group. The lyophilisate group's precorneal and conjunctival surface fluorescein concentrations were up to 34 times higher after 15 minutes.

In 1999 Diestelhorst et al reported on the tolerability and safety of the new drug delivery system. ${ }^{29}$ Our data confirm the safety and tolerability of the preservative-free lyophilisate when applying fluorescein to the human eye. The flexible handle strip is easy to use for patients, relatives, doctors, and hospital staff. The patients do not need to recline their heads $>60^{\circ}$ or sit or lie down. Compared with the tip of an eye bottle there is no risk of trauma or injury.

Higher drug concentrations remain in the tear film and better penetration to the ocular surface tissues is achieved. The higher drug concentration of the precorneal tear film and the conjunctiva represent a better pharmacokinetic equation. Accurate dosing is achieved by means of the lyophilisate. A depot effect and prolonged corneal concentration can be achieved by selecting different polymers. A larger amount of drug remains at the cul de sac. This may lead to reduced concentrations in eye preparations.

The possibility of an increase in dosage of a given medication upon reaching the inner eye after administration seems promising. Lyophilisates are manufactured at physiological $\mathrm{pH}$ and do not need preservatives for stability reasons. The lyophilisate permits administration of hydrophilic and lipophilic drugs to connective tissues, wounds, or operating areas-for example, the application of steroids, antibiotics, or antimetabolites during surgery. The preservative-free lyophilisate may reduce the topical and systemic side effects of conventional eye drops used in ophthalmology, lead to effective therapy, and help to increase patient compliance. 
The greater intraocular bioavailability of fluorescein from the lyophilisate relative to the solution suggests that it may be a useful method for delivering substances to the eye.

\section{ACKNOWLEDGEMENTS}

The authors are grateful to A Dinslage for assistance in producing the clinical photographs

\section{Authors' affiliations}

S Dinslage, M Diestelhorst, Department of Ophthalmology, University of Cologne, Germany

A Weichselbaum, R Süverkrüp, Department of Pharmaceutical Technology, University of Bonn, Germany

Presented in part at ARVO 2000 (No 4063).

Correspondence: Professor M Diestelhorst, Department of Ophthalmology, University of Cologne, Joseph-Stelzmann-Strasse 9, 50931 Cologne, Germany; michael.diestelhorst@medizin.uni-koeln.de

Accepted for publication 17 September 2001

\section{REFERENCES}

1 Burstein NL. Corneal cytotoxicity of topically applied drugs, vehicles and preservatives. Surv Ophthalmol 1980;25:15-30.

2 Gasset AR, Ishii MD, Kaufmann HE, et al. Cytotoxicity of ophthalmic preservatives. Am J Ophthalmol 1977;78:98-105.

3 Khalili $\mathbf{M}$, Diestelhorst M, Krieglstein GK. Long-term follow-up of 700 trabeculectomies. Klin Monatsbl Augenheilkd 2000;217:1-8

4 Fraunfelder FT. Drugs used primarily in ophthalmology. In: Drug-induced ocular side effects. 4th ed. Baltimore: William and Wilkins, 1996:420-33.

5 Alani SD. The ophthalmic rod: a new ophthalmic drug delivery system. Graefes Arch Clin Exp Ophthalmol 1990;228:297-301

6 Diestelhorst $M$, Krieglstein GK. The ocular tolerability of a new ophthalmic drug delivery system (NODS). Int Ophthalmol 1994;18:1-4.

7 Shell JW. Ophthalmic drug delivery systems. Drug Dev Res 1984;6:245-61

8 Le Bourlais C, Acar L, Zia H, et al. Ophthalmic drug delivery systems-recent advances. Prog Ret Eye Res 1998;17:33-58.

9 Maurice DM, Mishima S. Ocular pharmacokinetics. In: Sears ML, ed. Pharmacology of the eye: handbook of experimental pharmacology. New York: Springer, 1984:69.

10 Zaki I, Fitzgerald P, Hardy JG, et al. A comparison of the effect of viscosity on the pre-corneal residence of solutions in rabbit and man. $J$ Pharm Pharmacol 1986:38:463.
11 Kessler C, Bleckmann H, Kleintges G. Influence of the strength, drop size and viscosity of metipranolol eye drops on the concentration of the substance in human aqueous humour. Graefes Arch Clin Exp Ophthalmol 1991;229:452-6.

12 Mishima S. Clinical pharmacokinetics of the eye. Proctor lecture. Invest Ophthalmol 1981;21:504.

13 Schoenwald RD. Ocular pharmacocinetics/pharmacodynamics. In: Mitra AK, ed. Ophthalmic drug delivery systems. New York: Marcel Dekker, 1993

14 Lederer CM, Harold RE. Drop size of commercial glaucoma medications. Am J Ophthalmol 1986;101:691-4.

15 Brown RH, Lynch MG. Drop size of commercial glaucoma medications [letter]. Am J Ophthalmol 1986;102:673-4.

16 Charap AD, Shin DH, Petursson G, et al. The effect of varying drop size on the efficacy and safety of a topical beta-blocker. Ann Ophthalmol 1988;21:351-7.

17 Mishima S, Gasset A, Klyce SD, et al. Determination of tear volume and tear flow. Invest Ophthalmol 1966;5:264-76.

18 Patton TF, Franceur M. Ocular biovailability and systemic loss of topically applied ophthalmic drugs. Am J Ophthalmol 1978;85:225.

19 Chrai SS, Makoid MC, Eriksen SP, et al. Drop size and initial dosing frequency problems of topically applied ophthalmic drugs. J Pharm Sci 1974;63:333.

20 Farris RL, Stuchell RN, Mandell ID. Basal and reflex human tear analysis. I Physical measurements: osmolarity, basal volumes, and reflex flow rate. Am Acad Ophthal 1981;88:852.

21 Burstein NL. Comeal cytotoxicity of topically applied drugs, vehicles and preservatives. Surv Ophthalmol 1980;29:15-30.

22 Gasset AR, Ishii Y, Kaufman HE, et al. Cytotoxicity of ophthalmic preservatives. Am J Ophthalmol 1974;78:98-105.

23 De Saint JM, Brignole F, Bringuier AF, et al. Effects of benzalkonium chloride on growth and survival of Chang conjunctival cells. Invest Ophthalmol Vis Sci 1999;40:619-30.

24 De Saint JM, Debbasch C, Brignole F, et al. Toxicity of preserved and unpreserved beta-blocker eyedrops in an in vitro model of human conjunctival cells. J Fr Ophtalmol 2000;23:111-21.

25 Baudouin C, Pisella PJ, Fillacier K, et al. Ocular surface inflammatory changes induced by topical antiglaucoma drugs: human and animal studies. Ophthalmology 1999;106:556-63.

26 Becquet F, Goldschild M, Moldovan MS, et al. Histopathological effects of topical ophthalmic preservatives on rat corneoconjunctival surface. Curr Eye Res 1998;17:419-25.

27 Broadway DC, Grierson I, OBrien C, et al. Adverse effects of topical antiglaucoma medication. I. The conjunctival cell profile. Arch Ophthalmol 1994;112:1437-45.

28 Nuzzi R, Finazzo C, Cerruti A. Adverse effects of topical antiglaucomatous medications on the conjunctiva and the lacrymal response. Int Ophthalmol 1998;22:31-5

29 Diestelhorst M, Grunthal S, Süverkrüp R. Dry drops: a new preservative-free drug delivery system. Graefes Arch Clin Exp Ophthalmol 1999;237:394-8. 